\title{
Blogs e as transformações do Jornalismo
}

\author{
Claudia Irene de Quadros ${ }^{1}$ \\ Universidade Tuiuti do Paraná \\ claudiaquadros@hotmail.com \\ Ana Paula da Rosa 2 \\ Universidade Tuiuti do Paraná \\ anapaular@annex.com.br \\ Josiany Vieira 3 \\ Universidade Tuiuti do Paraná \\ josianyvieira@yahoo.com.br
}

\begin{abstract}
Resumo: Dois blogs jornalísticos, com características diferentes, são analisados em contraste com a cobertura do jornalismo digital brasileiro sobre o primeiro depoimento do deputado federal Roberto Jefferson na CPI dos Correios. A proposta do trabalho tem a intenção de observar o impacto do blog no jornalismo, acompanhando aspectos como atualização da notícia, recursos hipermidiáticos $e$ conteúdo. Duas principais questões permeiam este artigo: Os blogs são um complemento da mídia? Existe um novo modo de fazer jornalismo com os blogs? Sem a pretensão de chegar a uma conclusão definitiva, esse trabalho ainda demonstra que o blog pode ser utilizado como objeto e instrumento de pesquisa. As autoras desse artigo, a partir da criação de um próprio blog, deixam registradas as suas contribuições para etapas da presente experimentação.
\end{abstract}

Résumé: Deux blogs journalistiques, avec caractéristiques différentes, sont analyses en contraste avec la couverture du journalisme digital brésilienne sur le premier déposition du député fédéral Roberto Jefferson dans la CPI du Courrier. La proposition a l'intention d'observer l'impact du blog dans le journalisme, suivit aspects comme l'actualisation des nouvelles, recours au-dessus de la presse et contenu. Deux principales questions conduisent cet article: Les blogs sont un complément de la presse? Existe une nouvelle manière de faire journalisme avec les blogs? Sans la prétension d'arriver a une conclusion définitive, ce travaille démontre encore que le blog peut être utilisé comme objecte et instrument d'enquête. Les auteurs de cet article, d'après la création d'un blog propre, laissent registrées sa contribution par les étages de cette expérimentation.

\footnotetext{
${ }_{1}^{1}$ Claudia Irene de Quadros, doutora em Jornalismo pela ULL (Espanha), é professora do Programa MCL - Mestrado em Comunicação e Linguagens da Universidade Tuiuti do Paraná. ${ }^{2}$ Ana Paula da Rosa é jornalista pela Universidade de Passo Fundo (UPF) e mestranda do MCL.

3 Josiany Vieira é jornalista pela UTP e mestranda do MCL.
} 


\begin{abstract}
Two journalistic blogs, with different characteristics, are analysed in contrast with the Brazilian digital journalism coverage about the first deposition of the federal deputy Roberto Jefferson in the CPI of Postal Services. The proposition of this work has the intention of observe the blog impact on journalism, following aspects as notice update, hypermediatic resources and the content. Two principal questions permeate this article: Are blogs a media complement? Is there a new mode to make journalism with the blogs? Without the pretension of reaching a definite conclusion, this work still demonstrates that the blog can be used as object and instrument of research. The authoresses of this article, from the creation of their own blog, leave registered their contributions to the stages of the present experimentation.
\end{abstract}

Resumen: Dos blogs periodísticos, con características distintas, son analizados en contrapunto con la cobertura del periodismo digital brasileño sobre el primer testimonio del diputado Roberto Jefferson acerca del escándalo que pone en crisis el gobierno Lula. La propuesta del trabajo es plantear el impacto del blog en el periodismo, analizando aspectos como actualización de la noticia, recursos hipermidiáticos y contenido. Dos principales cuestiones forman parte de esto artículo: Los blogs son un complemento de los medios? Hay una nueva manera de hacer periodismo con los blogs? Sin la pretensión de llegar a una conclusión definitiva, ese trabajo aún demuestra que el blog puede ser utilizado como objeto y instrumento de investigación. Las autoras del artículo, desde la creación de un propio blog, dejan registradas las contribuciones para las fases de la presente experimentación.

Palavras-chave: blog; periodismo; web.

Mots-clé: blog; journalisme; web.

Keywords: blog; journalism; web.

Palabras clave: blog; periodismo; web.

\title{
1. Blogs: da origem ao desenvolvimento
}

Os blogs, que colocam em evidência o poder individual na rede das redes, têm servido para muitos propósitos desde o seu surgimento, quando Tim Berners Lee decidiu criar a sua página web e trocar informações com os seus colegas de trabalho. O termo blog, inserido em 2003 no dicionário 
Oxford da língua inglesa, foi cunhado pelo norte-americano Jorn Barger 4 . (Stutz, dez.1999). A revista Wired, na edição de dezembro de 1999, destaca que Barger criou o nome blog em 1997. No entanto, a Wikipedia5 - uma enciclopédia grátis disponível na Internet - traz dois nomes associados a palavra blog: Jorn Barger e Peter Merholz. Barger teria cunhado o termo weblog $($ web $+\log$ ) ao descrever o processo de registro na web. Entre abril e maio de 1999, Merholz teria escrito blog pela primeira vez no seu weblog para evitar uma cacofonia ${ }^{6}$. Blood (2002) relata que o termo ganhou visibilidade quando Cameron Barret escreveu, em 1999, um post7 intitulado Anatomia de um Blog no Camworld ${ }^{8}$, seu diário na Internet.

Desse modo, blogs são registros na World Wide Web. Desde 1997, quando proliferaram na rede, esses registros têm sido dos mais variados gêneros, como: diários pessoais, protestos, projetos, propaganda e notícias dos bastidores dos meios de comunicação. Todos com a necessidade de compartilhar uma idéia ou contar uma história para qualquer internauta disposto a participar ou não com comentários. Os blogs tomaram tal proporção que muitos meios da imprensa tradicional têm proibido os jornalistas do seu quadro funcional de manter um nas páginas web. "O New York Times, por exemplo, proíbe os jornalistas de manter blogs relacionados à sua área de atuação.” (Almeida, 2004). E precisam de autorização da redação do jornal para criar um blog sobre quaisquer outros assuntos. Nesse sentido, a imprensa norte-americana vive uma crise de identidade, tomando atitudes pouco democráticas com relação aos blogs jornalísticos.

A história desses blogs demonstra que esse poderoso instrumento de comunicação tem abalado as rotinas produtivas dos meios de comunicação de

\footnotetext{
4 Jorn Barger afirmar ter utilizado o termo blog pela primeira vez. O seu blog está na URL http://radio.weblogs.com/0123486/2005/06/24.html\#a2263, acessado em 8 de jul. 2005.

5 A Wikipedia está na URL: http://en.wikipedia.org/wiki/Main_Page

${ }^{6}$ A cacofonia (encontro ou repetição de sons que desagrada ao ouvido) foi evitada por

Merholz quando ele escreveu a frase " 'we blog' in the sidebar of his weblog”.

7 As atualizações de um blog são denominadas de posts.

8 A URL de Camworld é camworld.com
} 
massa. O primeiro furo de reportagem de um blog, com repercussão internacional, ocorreu no dia 18 de janeiro de 1998, quando o jornalista norteamericano Matt Drudge noticiou o escândalo entre Bill Clinton e a estagiária Mônica Lewinsky no seu diário denominado de drudgereport.com. Neste caso, a "Internet fue el medio usado para publicar las primeras informaciones y rumores sobre la historia de que Mónica Lewinsky, becaria de la Casa Blanca, había mantenido relaciones sexuales con el presidente de Estados Unidos” (De Quadros, 1999). Na época, grande parte da imprensa tradicional denominou esse blog de modo pejorativo, qualificando-o como "um panfleto digital”. É claro que, devido ao acesso até então desqualificado e irrestrito da mídia, um sem número de informações nada criteriosas pôde permear o meio.

Para Castells (2003: 129-130) a Internet é meio de comunicação de circulação muito mais rápida e ampla que todos os outros veículos da mídia tradicional. $\mathrm{Na}$ rede é possível encontrar informações sem credibilidade e também relevantes. "Foi o caso da primeira informação referente ao caso Mônica Lewinsky affair, divulgada por um jornalista freelance de Los Angeles, via seu boletim na Internet, enquanto a grande imprensa continuava avaliando a matéria."

Na tentativa de observar o impacto dos blogs no jornalismo brasileiro, procuramos analisar os blogs jornalísticos a partir de uma tipologia estabelecida com base nos estudos de Recuero (2003) e Scott (2004).

\section{Em busca de uma tipologia para os blogs jornalísticos}

Recuero (2003) acredita que há muitas possiblidades para classificar os milhares de blogs na rede mundial de computadores, mas optou em dividí-las em três categorias: diários eletrônicos ("fatos e ocorrências da vida pessoal de cada indivíduo"), publicações eletrônicas ("se destinam principalmente à informação) e publicações mistas ("misturam posts pessoais sobre a vida do autor e posts informativos"). Essa tipologia, no entanto, serve 
apenas como um caminho para a análise dos blogs jornalistícos, pois não consegue atender as variações desse gênero. Nesse sentido, Dória (2005) recorda que o blog informativo, "instrumento fantástico para quem quiser fazer imprensa com as próprias mãos”, pode ser de vários tipos: “de análise, de links em série, comentados ou não, apontando o que há de melhor publicado nas páginas. Ou até mesmo da boa e velha apuração: pega um telefone, conversa, descobre como funciona, publica.”

Com o propósito de encontrar uma categorização mais adequada aos blogs jornalísticos, as informações acima foram associadas a tipologia apresentada pelo escritor D. Travers Scott, que também possui um blog9. Segundo Scott (2004), com enfoque na tecnologia digital, os blogs podem ser divididos em dois períodos: protótipos de blogs e blogs contemporâneos, numa tradução livre. A primeira fase, a dos protótipos de blogs, era necessário conhecer a linguagem HTML e não havia uma preocupação com a temática. As pessoas, normalmente, dividiam com o usuário a sua lista de links favoritos de assuntos gerais ou temáticos. Todos, no entanto, com um só propósito, revelar os interesses pessoais do autor do blog. Aqui, na fase dos protótipos dos blogs, acrescentamos os diários instrutivos, com seus links de assuntos gerais ou temáticos. A sua diferença com os diários pessoais está na intenção de compartilhar um conhecimento em nome do avanço científico, sociocultural ou político.

$\mathrm{Na}$ atual fase, a dos blogs contemporâneos, a preocupação está no enredo e existem inúmeros programas gratuitos na rede para facilitar a sua disponibilização na web. Mais adiante, apresentaremos a sua categorização. Nesse estudo, são analisados dois blogs jornalísticos que se enquadram na esfera dos blogs contemporâneos. Para tanto, um quadro foi criado para ilustrar a tipologia desenhada a partir dos estudos da área e da observação sistemática dos blogs. No topo desse quadro, estão os protótipos de blogs, já

9 O blog de D. Travers Scott pode ser acessado pela seguinte URL: http://oneofthesethings.blogspot.com. 
categorizados, e os blogs contemporâneos de Scott. O avanço tecnológico facilitou o acesso e permitiu que o público também contasse a sua versão sobre um determinado fato, garantindo o desenvolvimento dos blogs contemporâneos. Em outras palavras, os blogs informativos romperam com o Império Romano que vivia os meios de comunicação de massa para entrar num período quase feudal, onde há e poderá haver mais centros de força e influência (Schell in Rosen, 2005). Ainda que os blogs informativos possam pertencer a um jornalista, cresce o número de pessoas com outra formação que utilizam essa ferramenta como meio de comunicação.

Conforme o quadro abaixo e à direita, os blogs contemporâneos podem ser assim divididos:

\begin{tabular}{|c|}
\hline PROTÓTIPOS DE BLOGS \\
\hline DIÁRIOS PESSOAIS \\
\hline Links para Assuntos Gerais \\
\hline Links temáticos \\
\hline DIÁRIOS INSTRUTIVOS \\
\hline Links para Assuntos Gerais \\
\hline
\end{tabular}

Quadros, 2005. Tipologia criada com base em Scott (2004) e Recuero (2003).

Os diários pessoais, na fase dos blogs contemporâneos, ganham mais recursos multimidiáticos e não se limitam ao uso de lista de links favoritos. Descrevem fatos da vida pessoal, com a intenção de tornar a sua figura pública ou para a autopromoção. Por exemplos: o diário com as histórias de uma adolescente na rede e o do jovem ator que descreve as suas potencialidades em 
cena. Nesses blogs, os visitantes têm condições de publicar comentários, mas o controle é individual. Cabe ao autor do blog manter ou não o post enviado.

Nos blogs coletivos mais de uma pessoa pode postar e editar. Os usuários/autores fazem parte de uma comunidade virtual que tem interesses em comum, com o objetivo de atender, normalmente, as próprias necessidades. Um administrador, contudo, é quem convida outros usuários/autores para fazer parte do blog, podendo retirar a qualquer momento o poder de edição oferecido. Nesse sentido, o blog coletivo concentra-se no poder de um indivíduo, pois a participação dos demais usuários/atores depende do desejo do administrador. Os posts dos demais usuários, que não têm o poder de edição, podem funcionar como nos diários pessoais, cabendo ao grupo mantê-los ou não.

O blog instrutivo, que pode ser construído por uma única pessoa ou por um grupo, surgiu com o objetivo de compartilhar informação e, assim, ampliar conhecimento. Na fase dos protótipos de blogs, esse tipo continha apenas links de assuntos gerais ou temáticos de um blogueiro, normalmente, pesquisador, como Tim Berners Lee. Na fase dos blogs contemporâneos, eles ganham recursos multimidiáticos e a facilidade no uso da tecnologia empregada também ampliou o número de blogueiros com outras profissões. $\mathrm{Na}$ Internet, é possível aprender e trocar idéias sobre as mais diversas áreas, como literatura, dança, matemática, astrofísica etc.

O diário informativo, feito de forma individual ou em grupo, também pode oferecer possibilidades de participação do usuário por meio de posts. Fazem parte dessa categoria os blogs jornalísticos, objetos de estudo desse trabalho. Os diários informativos são de assuntos gerais ou sobre um tema específico, como cultura, economia, política e outros. Independente do tema, eles ainda podem ser analíticos, opinativos, noticiosos ou um mix de um ou mais estilos. 
Os diários mistos, que na categorização de Recuero (2003) são denominados de publicações mistas por que os posts são pessoais e informativos, recebem esse nome no presente estudo pelo fato de possuir características de outros diários apresentados acima e categorizados no quadro demonstrativo.

\section{Blog: do objeto ao instrumento de pesquisa}

Aqui, analisamos os blogs dos jornalistas Ricardo Noblat e do Jorge Bastos Moreno. O primeiro, no dia 14 de junho, realizava uma produção independente, sem apoio financeiro de qualquer empresa. Hoje, Ricardo Noblat está associado ao Último Minuto, do IG. O segundo trabalha como correspondente em Brasília para o jornal O Globo e a sua versão digital. Ainda foram observados aspectos como atualização da notícia, recursos hipermidiáticos e de conteúdo.

Para esse estudo foi criado um blog intitulado mestrado $\mathrm{MCL}^{10}$ com a intenção de fazer dessa experimentação um laboratório transparente, pois como destaca Moles (1995:73) não é "possível fechar as portas ao futuro e ao exercício da razão". Na sociedade digital, a soma de conhecimento faz a ciência avançar e ainda valoriza o indivíduo. O blog de objeto passou a ser também instrumento de pesquisa, destacando o trabalho individual do resultado final. É importante ressaltar que o compromisso em acompanhar a cobertura do primeiro dia da CPI dos Correios, para posterior a análise, foi assumido por mais quatro pessoas em uma reunião presencial, no entanto, apenas três concluíram a investigação. A troca de e-mails também foi utilizada antes da postagem do material, mas acreditamos que a nossa primeira experiência na utilização dessa ferramenta poderá fortalecer as pesquisas na área de comunicação, unindo especialistas de várias outras instituições.

${ }^{10}$ A URL do MCL Mestrado é http://mestradomcl.blogspot.com 
Antes da análise propriamente dita cabe aqui a questão: é jornalismo o que vem sendo apresentado na blogosfera? Essa questão, já bastante debatida em blogs, sites ou outros veículos, têm o único interesse em mostrar opiniões diversas. O jornalista Pedro Dória (2005) acredita que há muitos blogs jornalísticos em outros países, mas no Brasil são ainda em número muito pequeno. "A maioria talvez não resulte em bom resultado, mas na quantidade sempre despontam bons nomes.” Os blogs informativos, no entanto, não precisam ser produzidos exclusivamente por jornalistas, também “podem ser de cidadãos conscientes dispostos a revelar informações que apenas eles têm acesso e a mídia deixa de divulgar por questões políticas, econômicas ou conformismo" (Quadros, 2005). Nesse sentido, o cidadão também ganha o papel de emissor na Internet, podendo interagir com os meios ou, na impossibilidade desta alternativa, construir o seu próprio veículo na rede das redes.

Para David Berlo a relação de interdependência entre o emissor e o receptor é uma condição essencial para a comunicação humana. Segundo o autor, para que a comunicação seja efetivada é preciso que haja uma influência mútua entre a fonte e quem recebe a mensagem, pois um precisa do outro para a própria existência. Além disso, seguindo a linha de pensamento de Berlo, toda ação comunicativa exige uma reação, que irá resultar em uma resposta, ou seja, num feedback. No entanto, o ideal da comunicação é a interação, que é a base da Internet.

"O termo interação denomina o processo de adoção recíproca de papéis, o desempenho mútuo de comportamentos empáticos. Se dois indivíduos tiram inferências sobre os próprios papéis e assumem o papel um do outro ao mesmo tempo, e se o seu comportamento de comunicação depende da adoção recíproca de papéis, então eles estão em comunicação por interagirem um com o outro. A interação é a meta, o ideal da comunicação humana"(BERLO: 1999, p.134-135)

No jornalismo feito pelos blogs essa interação parece ser ampliada, pois permite ao leitor participar de forma efetiva do meio. Alguns diários digitais 
tentam proporcionar a interação, mas, na verdade, limitam-se a oferecer apenas algumas alternativas para o internauta escolher. Nesse caso, ao invés da interação ocorre apenas um ato de reação. Na Internet, no entanto, pode ocorrer a troca de dados e a interdependência defendida por Berlo é bastante explorada pelos blogs jornalísticos, onde a fonte passa a prescindir da audiência com seus comentários, suas contribuições e até suas críticas.

Poderia se dizer então que a comunicação oferecida pelos blogs é a ideal? Ainda é muito cedo para responder essa questão. Nesse sentido, há necessidade de mais pesquisas sobre a produção e recepção dos blogs, pois muitos dos seus efeitos na sociedade ainda não são conhecidos e a rotina produtiva dos blogs, às vezes, precisam ser mudadas por conta do mau uso por parte de uma audiência e o surgimento de novas tecnologias. Por exemplo, o jornalista Ricardo Noblat, que nunca censurou os posts enviados ao seu blog anunciava que teria de controlá-los, pois o blog estava recebendo muitos posts provenientes de poucas máquinas. Neste sentido, "haverá dispositivo para bloquear automaticamente mensagens" repetidas com o mesmo IP (Internet Protocol) e que estão sendo utilizadas para atravancar o servidor. Essa atitude do jornalista foi tomada em reação à postagem de um número superior a mil comentários idênticos ou muito parecidos. Isso, no entanto, não significa que Noblat desvalorize a participação do público, muito pelo contrário. "Todo cidadão pode ser jornalista, basta saber ver, ouvir e contar", proclamava Noblat no dia 14 de junho, às 13 h57min.

\section{Blogs: a informação no centro do palco}

O jornalismo está passando por um momento de transformação, onde conceitos e formas de produção da notícia são reavaliados em virtude da própria mutação por qual passa a sociedade. Mediante as tecnologias avançadas da comunicação que surgem e se difundem o que pode ser entendido como jornalismo? Para Eduardo Meditsch (1992) o jornalismo se 
sustenta num tripé formado pelas linguagens, pelas tecnologias e pelos modos de conhecimento. Meditsch defende que o jornalismo tem uma ampla importância social no sentido de produzir conhecimento e de torná-lo acessível a todas as pessoas. Dentro desta ótica a Internet encaixa-se perfeitamente. O jornalismo digital, que vem a cada dia ganhando mais adeptos, trabalha com uma linguagem, ainda não bem formatada, que valoriza a fórmula da informação - pílula, fácil de ler e para ser consumida rapidamente, onde o que realmente importa são os fatos e a velocidade com que eles são disponibilizados. Na era do jornalismo digital a mídia sincroniza os tempos e permite que se tenha a ilusão de um tempo real que não pode ser apreendido.

Dessa forma,. o jornalista precisa, antes de todos, estar preparado para a Internet. "Se conseguir tornar-se o grande mediador que sempre foi, o jornalista retomará, em outro suporte, o papel de iluminador, que dá visibilidade ao outro, ao escolhido, e recolhe os benefícios do esclarecimento".(Silva, 2000:34). O jornalista Ricardo Noblat, por exemplo, cita e comenta informações de vários veículos de comunicação (O Globo, Jornal do Brasil, rádio CBN, Agência Reuters, Folha de São Paulo, sites de políticos, IG, Isto É, Veja OnLine, entre outros). No dia 14 de junho, durante o primeiro dia de cobertura da CPI dos Correios, o blog de Noblat bateu recorde de audiência com 55.763 visitantes, também utilizando as referidas fontes para a contextualização dos fatos. Os blogs, neste sentido, são um novo tipo de jornalismo, onde o mais importante não é como a matéria foi produzida, se foi um repórter que apurou os dados diretamente com a fonte, se é uma cópia do que os demais veículos publicaram... O que importa é a informação, esta escrita de forma sintética, quase como uma crônica, onde os seus responsáveis assumem posições e lançam mão da ironia, do texto poético e de todos os recursos técnicos para transmitir da forma mais eficaz possível esta informação. A notícia baseada na fórmula da pirâmide invertida, ou seja, o mais importante em primeiro lugar, não é abandonada completamente, mas 
os dados essenciais da informação são transmitidos sem que seja necessária uma ordem, uma hierarquia de valores. A palavra-chave nos blogs de jornalismo é a instantaneidade, propiciar ao leitor-ator-internauta (leitor de jornal, ator da notícia e internauta por usar o suporte da internet) uma espécie de liberdade para interpretar e, acima de tudo, se posicionar sobre os fatos apresentados e atualizados de forma tão rápida quanto os frames das próprias páginas.

Os blogs, de certa forma, revitalizaram a Internet em vários campos, sobretudo no jornalístico. Da simples transposição do conteúdo produzido nos jornais impressos como ocorreu num primeiro momento na rede mundial de computadores, o jornalismo digital vive hoje o período de evolução, onde já é possível observar características próprias de um meio ainda em construção. Nesse sentido, muitos guardiães da notícia, acostumados com a rotina da imprensa, são obrigados a reavaliar a importância dos blogs jornalísticos que conseguem dar voz aos cidadãos. Normalmente, os jornalistas dos meios tradicionais agem como soubessem tudo que o público deseja. “(...)Os jornalistas justificam a sua intromissão e os seus excessos alegando que são representantes do público, colocando as perguntas que os seus concidadãos colocariam se tivessem ocasião de se encontrarem com os presidentes e senadores. Mas de facto fazem perguntas que só interessem aos políticos profissionais(...)" (Fallows, James apud Traquina e Mesquita, 2003: 24). Na Web, não é preciso aguardar mais a vontade dos meios de comunicação, podese exercer a cidadania nos blogs ou em outros espaços que estão surgindo. Nos blogs jornalíticos, percebemos que jornalistas e cidadãos estão construindo uma história juntos.

Dessa união, surge o fortalecimento do jornalismo. A mídia tradicional já observou esse fenômeno. Nos Estados Unidos, nas eleições presidenciais de 2004 a imprensa norte-americana repercutiu informações políticas relevantes dos blogs. (Hewitt, 2005). No Brasil, a versão digital do jornal O Globo 
demonstra que não precisa nadar contra a corrente como faz o The New York Times quando o assunto é blog. Os editores do O Globo Online decidiram criar blogs para todos os seus colunistas, acreditando no poder individual e no interesse do público que busca notícias na Internet pelos blogs. Será que interesses empresarias não vão interferir na isenção desses blogs? Essa é uma questão que merece ser refletida, mas em uma outra oportunidade. No entanto, registramos que essa é uma nova forma de fazer jornalismo que sempre terá observadores críticos dispostos a protestar em casos de omissão, manipulação ou com a falta da verdade.

\section{Análises: blogs e sites jornalísticos}

Dois blogs jornalísticos, com características diferentes, são analisados em contraste com a cobertura do jornalismo digital brasileiro, tendo como foco de estudo o primeiro depoimento do deputado federal Roberto Jefferson na CPI (comissão parlamentar de inquérito) dos Correios, no dia 14 de junho. Os blogs, como dito anteriormente, são de Ricardo Noblat e Jorge Bastos Moreno. E os meios são as versões digitais da Folha de São Paulo e O Globo. É importante que fique claro que o objetivo deste estudo de caso não é identificar a concorrência entre os meios tradicionais e os on-line, mas sim verificar o impacto dos blogs no jornalismo digital sobre o que foi noticiado no dia 14 de junho, quando foi instaurada a CPI dos Correios.

O destaque do dia foi mesmo o primeiro depoimento do deputado do PTB, Roberto Jefferson, na comissão de ética da Câmara de Deputados com relação às denúncias de que o PT estaria pagando uma mesada, o "mensalão", para os aliados da base governista. Embora os blogs e os jornais digitais, como Globo e Folha, tenham tratado, praticamente, dos mesmos assuntos ao longo do dia 14, a chamada terça-feira negra, as coberturas foram realizadas de forma muito distinta. 
Os blogs de Ricardo Noblat (www.noblat.blig.ig.com.br) e de Jorge Bastos Moreno (www.oglobo.globo.com/online/blogs/moreno) dedicaram o dia 14 inteiro, exclusivamente, a assuntos referentes à CPI e às denúncias de corrupção com atualizações feitas com uma diferença média de 5 minutos. Os jornais digitais, pelo pesquisado, também buscaram atualizar seus dados no menor espaço de tempo possível, mas a linguagem jornalística dos sites, ainda muito baseada na do jornalismo impresso, acabou por determinar uma perda de espaço para os blogs. Além disso, assuntos como o julgamento de Michael Jackson, atentados no Iraque, Copa das Confederações, rebelião em presídio e a definição de taxas de juro no país dividiram a atenção e a pauta dos jornais digitais.

Ricardo Noblat, por exemplo, se antecipou às emissoras de televisão e aos jornais ao divulgar que Roberto Jefferson teria se disponibilizado a ter quebra de sigilo bancário e telefônico. Já Jorge Bastos Moreno cogitou, antes de qualquer outro veículo, que o ministro da Casa Civil, José Dirceu, deixaria o cargo. Acompanhar os blogs jornalísticos, neste sentido, passou a ser uma condição sine qua non para quem deseja estar bem informado. Ambos os jornalistas contextualizam os fatos e deixam bem claro o que é opinião. Noblat, na nova versão do seu blog, sempre destaca nos últimos parágrafos de seus posts que ali está a sua opinião. Assim, experiência, credibilidade e respeito são somados a um contrato de fidelização entre usuário/ator e jornalista/blogueiro. O Globo, durante o dia 14 de junho, se limitava a destacar na sua página principal uma chamada para o blog do Moreno para quem desejasse mais detalhes da CPI, demonstrando o blog como um complemento importante do site jornalístico. Moreno, no post intitulado a “Chegou a hora da verdade", de 14 de junho de 2005, às 13ho8min, reforçava a importância do blog, destacando que passaria o dia "buscando informações além da cobertura convencional". 
A seguir serão breve analisados alguns aspectos desses blogs contemporâneos, categorizados como blogs informativos de cunho noticioso e opinativo:

Quanto ao valor da notícia - Os blogs deram mais atenção à cobertura do depoimento de Roberto Jefferson na Câmara do que os jornais digitais. Não que os demais veículos não tenham disponibilizado informações sobre o caso, mas tiveram de dividir espaço com outros assuntos que foram surgindo durante o dia.

É importante destacar que a crise política brasileira tornou-se um assunto de inegável pertinência, sendo que a grande diferença dos blogs para os jornais digitais em termos de abordagem da notícia foi o grau de aprofundamento. Por mais que os blogs trabalhem com textos bem curtos, com frases e com opiniões, ao que parece as informações foram mais completas, mais amplas e receberam maior destaque, tanto que os jornalistas responsáveis pelos blogs não ousaram tocar em outros assuntos durante o dia 14. A pauta foi constituída somente de dados sobre a corrupção e a crise política, desde os bastidores. Dessa forma, assim como as rádio all news são referências para o cidadão durante um grande acontecimento, os blogs temáticos, como os de Noblat e Moreno, podem ganhar mais atenção do público, como aconteceu com a Guerra do Iraque, as eleições americanas e agora a CPI dos Correios. Além de servirem como fonte para a mídia, os blogs também têm sido importantes como formadores de opinião. O deputado federal Eduardo Suplicy, numa declaração à TV Senado, disse ter assinado a CPI dos Correios depois de ler os comentários postados no blog de Ricardo Noblat.

Muitas vezes as notícias eram dadas primeiro nos blogs e depois se transformavam em matérias nos demais veículos on-line, pois assim já se tinha uma prévia do interesse público. Neste sentido, Muniz Sodré (1996) defende que a noção de interesse público é crucial para o produtor da notícia. 
"Para o código jornalístico, o interesse por um evento está em relação direta com a sua atualidade e sua significação social e em relação inversa com a distância psicológica entre o lugar do fato e o do leitor" (p.140). No entanto, essa relação de proximidade é muito relativa na web, já que o fluxo de informações é muito amplo e é o leitor-ator-internauta que define como será sua leitura, qual caminho seguirá.

Quanto à atualização - Como comentado anteriormente, os blogs foram atualizados com mais freqüência que os sites dos jornais e rádios. Como a linguagem dos blogs é diferente, mais coloquial, exige menor esforço de produção do tipo entrevistas e fotografias, a atualização é feita quase em tempo real, numa média de 5 minutos, já nos sites jornalísticos esse período passa a ser de 10 a 30 minutos. Conforme Pierre Lévy (2000) o tempo real, que é a busca incessante na rede, designa a imediatez da transmissão, do cálculo e da resposta, o tratamento e a apresentação das informações. "No horizonte das acelerações, no olho do ciclone das velocidades, o tempo real, imóvel, move o espaço-tempo das mercadorias. O tempo real é a realidade do tempo mercantil" (p.153) Embora os jornais e as rádios na web também persigam o ideal de tempo real, como definido por Lévy, na prática há uma diferença considerável do fato até a notícia ser disponibilizada na rede, tudo porque embora se esteja rumando para um novo jornalismo, ainda se faz muito uma transposição das práticas do impresso. E a questão mercantil também é relevante, já que jornais como O Globo e Folha são antes de tudo empresas e adotam posturas um tanto mais cuidadosas que os blogs. No caso do Globo, por exemplo, o blog de Moreno é uma alternativa para que se diga o que se quer dizer sem que o nome do jornal como um todo esteja em jogo.

Quanto ao conteúdo - Os jornais na web ofereceram aos usuários uma cobertura ampla, com recursos multimídia, ou seja, com a utilização de fotografias, entrevistas em áudio, transcrições dos discursos e seqüências de imagens. Até mesmo a repercussão das denúncias de corrupção em outros 
países foi apresentada. Segundo Pollyana Ferrari (2003), o conteúdo tornouse a palavra da moda no tempo da proliferação de sites. "Os elementos que compõem o conteúdo on-line vão muito além dos tradicionalmente utilizados na cobertura impressa - textos, fotos e gráficos. Pode-se adicionar seqüências de vídeo, áudio e ilustrações animadas. Até mesmo o texto deixou de ser definitivo"(p.39)

No entanto, os blogs apresentaram um conteúdo diferenciado, sem fotografias ou gravações, mas com textos curtos, frases na ordem direta, geralmente sem a utilização das tradicionais "aspas" do jornalismo impresso. O destaque foi mesmo para a informação, para a transposição de trechos do depoimento do deputado do PTB. O blog de Ricardo Noblat apresentou um conteúdo mais amplo que o de Moreno, pois além de ser atualizado constantemente desde as primeiras horas do dia, as notícias disponibilizadas valeram-se de alguns recursos multimídia como música ( a seleção da Música do Dia) e charges. Durante a cobertura, Noblat indicava caminhos para o usuário refletir sobre os fatos apresentados na CPI dos Correios, repercutindo as denúncias do deputado Roberto Jefferson. Ao final do depoimento, mostrou ao usuário um pouco dos bastidores da política. Entusiasmado com o número de acessos no seu Blog,, Noblat mostra que o público tem interesse nas questões políticas do país e que o jornalismo cor de rosa, feito com base em fofocas de celebridades, pode dar lugar a um jornalismo público, participativo.

Quanto à tecnologia - Para que um site na era do jornalismo digital tenha eficácia ele precisa respeitar alguns critérios que definem a acessibilidade. A usabilidade, definida por Pollyanna Ferrari (2003) como um conjunto de características de um produto que definem seu grau de interação com o usuário, é um deles. " Na Internet, onde cada vez mais será preciso prender a atenção do leitor, tanto na oferta de conteúdo como na prática do ecommerce, a usabilidade assume papel essencial" (p. 60) Muitos fatores fazem 
com que um site seja bastante utilizado, por exemplo se ele atende às necessidades do cliente, como as tarefas solicitadas pelo usuário são realizadas e o tempo de espera entre uma ação e uma resposta. Além disso, todo o design do site conta pontos no quesito usabilidade. Nos blogs a usabilidade é um ponto forte, pois de posse do endereço correto na web são necessários poucos cliques no mouse para acessar o conteúdo e não há muitas ilustrações, geralmente apenas uma duas fotos ou até mesmo só a foto do autor. O design das páginas é, no caso dos dois blogs estudados, bem limpo, sem a utilização de fios ou cores fortes. Mesmo quando há cores de fundo elas não entram em conflito com o texto escrito.

Outro ponto positivo dos blogs é o sistema de exposição das matérias jornalísticas, que seguem o estilo das colunas nos jornais impressos, textos curtos e dispostos na vertical, sem que seja necessário abrir novas páginas para acessar colunas anteriores. As que já não estão mais na página principal podem ser acessadas facilmente clicando em links de arquivo. Os jornais $\mathrm{O}$ Globo e Folha também possuem uma boa usabilidade, embora sejam construídos na horizontal em função da quantidade de matérias que contêm a página principal. $\mathrm{O}$ número de fotos nos dois jornais não é elevado $\mathrm{e}$ geralmente são pequenas, porém são mantidas as mesmas fotografias por longos períodos e só os textos atualizados, o que se torna num ponto negativo pois o leitor pode ter a impressão de estar lendo uma matéria velha. Até porque, muitas vezes, os jornais apenas substituem a chamada principal, mantendo todos os demais textos abaixo, sem situar o leitor recém-chegado que não acompanhou toda a cobertura e que, dificilmente, irá abrir todos os links de matérias disponíveis.

Com relação ao número de cliques, eles aumentam conforme o site. Por exemplo, no Globo há um menu na lateral esquerda da página que permite acessar só o conteúdo de interesse, embora na página principal estejam disponíveis outras inúmeras informações que para serem lidas na íntegra 
precisam ser acessadas separadamente. Neste processo, em alguns momentos, antes do conteúdo ser disponibilizado, propagandas de empresas ou produtos à venda aparecem na tela.

No que diz respeito ao banco de dados a Internet, pelo apurado, é extremamente eficaz. Os arquivos, tanto das colunas dos blogs como das notícias dos jornais e rádios on-line, são amplos, podendo ser recuperadas matérias e entrevistas de vários dias e, às vezes, de meses. No caso dos jornais Folha e Globo alguns links com o que já foi noticiado sobre o assunto são colocados no pé das matérias, favorecendo assim, para os interessados, ampliar os assuntos e retomar o que já foi publicado, tudo ao alcance de apenas alguns cliques no mouse.

Por fim, a tecnologia multimídia que também conta pontos para a acessibilidade está cada vez mais sendo aprimorada. No site da rádio $\mathrm{CBN}$ as entrevistas feitas com parlamentares sobre o mensalão e a CPI dos Correios foram disponibilizadas, bastando esperar alguns segundos para que o conteúdo fosse baixado no computador do usuário. As redes de televisão na web também aproveitam suas produções para colocar à disposição dos usuários da rede seqüências de imagens e áudio. Neste ponto, os blogs perdem para os sites jornalísticos tidos como tradicionais, porque ainda não trabalham com toda a capacidade tecnológica que a Internet possui.

\section{Algumas considerações}

Vale destacar que a rotina produtiva dos blogs jornalísticos aqui analisados são bastante conhecidos, divulgados pela mídia tradicional e pertencentes a dois jornalistas experientes e respeitados pelo público e por seus colegas de profissão. A pesquisa sobre blogs jornalísticos precisa ser acompanhada neste período de evolução do jornalismo digital, registrando e analisando o seu impacto sobre os demais veículos de comunicação. Nesse sentido, blogs de pessoas comuns devem ser tomados como objetos de 
estudos. É preciso registrar esse momento histórico por qual passa o jornalismo em todo o mundo, além de incentivar o uso da Internet entre os cidadãos. Afinal, na Sociedade do Conhecimento o fluxo de informação é livre, o problema consiste no seu acesso restrito.

O presente artigo aponta que o desenvolvimento da tecnologia pode ser utilizado em benefício do jornalismo, independente das transformações provocadas no exercício da profissão do jornalista. O importante é a informação que todo cidadão tem direito.

\section{REFERÊNCIAS}

ALMEIDA, Alexandre Cruz. Os jornalistas e os Blogs in Blog: Liberal, libertário, libertino. Postado em o9 de abril de 2004, disponível em http://www.sobresites.com/alexandrecruzalmeida/artigos/jornalistas. htm, acessado em 14 de junho de 2005.

BERLO, David K. O processo da comunicação: Introdução à Teoria e à Prática. $9^{\text {a }}$ edição. São Paulo: Martins Fontes, 1999.

BLOOD, Rebeca. The Weblog Handbook: Practical Advice on Creating and Maintaining your Blog. Cambridge: Perseus Publishing, 2002.

CASTELLS, Manuel - A Galáxia da Internet, Rio de Janeiro, Jorge Zahar Editor, 2003

DE QUADROS, Claudia Irene - 1999; Clinton-Lewinsky: el escándalo que comezó en la Red, Revista Latina de Comunicación Social, número 20, agosto de 1999, La Laguna (Tenerife), disponível em www.ull.es/publicaciones/latina/a1999eag/54cla.htm, acessado em 15 de junho de 2005.

DE QUADROS, Claudia Irene. Jornalismo Público com a Internet: uma proposta para incentivar a democracia, trabalho apresentado no III Seminário Internacional Latino-Americano de Pesquisa em Comunicação, São Paulo, 13 de maio de 2005.

DÓRIA, Pedro. Cadê os blogs informativos?, 7/05/2005, disponível em http://observatorio.ultimosegundo.ig.com.br/artigos.asp?cod=328ASP 010, acessado em 15 de julho de 2005.

FERRARI, Pollyana. Jornalismo Digital. São Paulo: Contexto, 2003. 
HEWITT, Nelson. Blog: Undestanding the Information Reformations That's Changing Your World, Nashville, 2005.

LÈVY, Pierre. A inteligência coletiva: por uma antropologia do ciberespaço. $3^{\text {a }}$ edição. São Paulo: Edições Loyola, 2000.

MOLES, Abraham. As Ciências do Impreciso, Porto, Edições Afrontamento, 1995.

MEDITSCH, Eduardo. O conhecimento do jornalismo. Florianópolis: Ed. UFSC, 1992.

TRAQUINA, Nelson e Mesquita, Mário (orgs). Jornalismo Cívico. Lisboa, Livros Horizonte, 2003.

RECUERO, Raquel da Cunha. Weblogs, Webrings e Comunidades Virtuais, 2003, disponível em

http://www.pontomidia.com.br/raquel/webrings.pdf, acessado em 18 de julho de 2004 .

SCHELL, Orville in ROSEN, Jay. Bloggers vs. Journalists is Over. 15 de Janeiro de 2005, disponível em http://journalism.nyu.edu/pubzone/weblogs/pressthink/2005/01/15/ berk_pprd.html, acessado em 19 de julho de 2005.

SCOTT, D. Travers. Blog Invasion! What are they? Where did they came from?, Writing \& Presentation for Digital Media, CMU597, 26 de maio, 2004, disponível em http://students.washington.edu/travers/blogs/BlogsScott.pdf, acessado em 16 de junho de 2005.

SILVA, Juremir Machado da. A miséria do jornalismo brasileiro: As (in) certezas da mídia. Petrópolis, RJ: Vozes, 1999.

SODRÉ, Muniz. Reiventando a cultura: a comunicação e seus produtos. Petrópolis, RJ: Vozes, 1996.

STUTZ, Michael. Log On. Revista Wired, dezembro de 1999, disponível em http://www.wired.com/wired/archive/7.12/eword.html?pg=7, acessado em 15 de junho de 2005. 